\title{
Study on the Behavior of the
} Minimum Quantity Lubricant - MQL

Centro Federal de Educação Tecnológica de Minas Gerais - CEFET-MG

Av. Amazonas, 5253 - Bairro Nova Suíça 30480-000 Belo Horizonte, Minas Gerais. Brazil Irsilva@deii.cefetmg.br

E. C. Bianchi

R. E. Catai

R. Y. Fusse

T. V. França

and P. R. Aguiar

UNESP - Universidade Estadual Paulista - Bauru Department of Mechanical Engineering Av. Luiz carrijo Edmundo Coube, $s / n$ 17033-360 Bauru, SP.Brazil bianchi@feb.unesp.br rcatai@feb.unesp.br aguiarpr@feb.unesp.br Technique Under Different Lubricating and Cooling Conditions
When Grinding ABNT 4340 Steel

Energy consumption, air pollution and industrial waste have received special attention from public authorities in recent years. The environment has become one of the most important subjects in the context of modern life, for its deterioration impacts the quality of life populations. Driven by pressure from environmental agencies, politicians have drawn up ever stricter laws aimed at protecting the environment and preserving energy resources. All these factors have led industry, research centers and universities to focus their efforts on researching alternative production processes, creating technologies to minimize or avoid the production of environmentally aggressive residues. Up to a few years ago, the main objective of manufacturing plants was to produce goods aimed at satisfying technological and economic aspects. Green, or "dry" machining and Minimum Quantity Lubricant (MQL) machining have caught the attention of researchers and technicians in the area of machining as an alternative to traditional fluids. Thus, this work proposes to explore the MQL concept in the grinding operation. Although its advantages allow one to predict a growing range of applications for $M Q L$, the variables of influence to be considered and the effects on the results of the process have so far been little studied. Grinding involves several input parameters but, to date, little attention has been focused on the form and quantity of cutting fluid applied to the process. The condition and rate of cutting fluid applied directly influences some of the process's output variables. This work, therefore, analyzes the behavior of the MQL technique under different lubrication and cooling conditions, developing an optimized fluid application methodology based on the creation of a special nozzle through which a minimum amount of oil is pulverized in a compressed air stream. The evaluation of the technical performance of MQL in grinding, using aluminum oxide and superabrasive CBN (cubic boron nitride) grinding wheels, consisted of an experimental analysis of the behavior of the tangential cutting force, $G$ ratio, roughness and residual stress. The results presented herein allowed us to evaluate the behavior of the MQL technique in the grinding process, thus contributing toward an environmentally friendly technology.

Keywords: Grinding, tangential cutting force, $G$ ratio, roughness, residual stress, CBN and $M Q L$

\section{Introduction}

The conventional cutting fluids utilized in grinding are considered a problem for manufacturers, since these substances can seriously damage human health and environment. Environmental concerns have become increasingly important to productive processes, allied with their economic and technological aspects. Galvanized into action by pressure from environmental agencies, politicians have imposed ever stricter legislation to protect the environment and preserve energy resources. These combined factors have driven the industrial sector, research centers and universities to investigate alternative production processes, creating technologies that minimize or avoid the production of environmentally aggressive residues. Large quantities of emulsion-based cooling fluids for machining are still widely used in the metal working industry, generating high consumption and discard costs and impacting the environment. The increasing need for environmentally friendly production techniques and the rapid growth of cutting fluid disposal costs have justified the demand for an alternative to machining processes using fluids. Over the last decade, however, the goal of research in this field has been to restrict as much as possible the use

Paper accepted May, 2005. Technical Editor: Anselmo.Eduardo Diniz. of cooling fluids and/or lubricants in metal-mechanical production processes. Dry machining and Minimum Quantity Lubricant (MQL) machining have become the focus of attention of researchers and technicians in the field of machining as an alternative to traditional fluids (Sahm \& Schneider, 1996; Dunlap, 1997; Klocke et al, 1998; Novaski \& Dörr, 1999 and Machado \& Diniz, 2000).

The specific function of cutting fluid in the machining process is to provide lubrication and cooling to minimize the heat produced between the surface of the part and the tool. However, eliminating these fluids, their positive influence on machining is also lost, since cutting fluid is an important technological parameter in machining. Their drastic reduction or even complete elimination may undoubtedly lead to increased temperatures in these processes, decline in cutting tool performance, loss of dimensional precision and geometry of the parts, and variation in the machine's thermal behavior. An important function of cutting fluid which is often disregarded but which plays a decisive role in practice is its usefulness in the transportation of chips (cleanliness). When abrasive tools are used, a reduction in cutting fluid can make it difficult to keep the grinding wheel's pores clean, favoring their tendency to clog and thereby aggravating the aforementioned negative factors. The relative importance of each of the functions also depends on the material being machined, the type of tool employed (defined or undefined geometry), the machining conditions, the surface finishing and the dimensional quality and 
shape required (Klocke \& Eisenblatter, 1997; Brockhoff \& Walter, 1998 and Machado \& Diniz, 2000).

The purpose of this work is to evaluate the performance of the MQL technology applied to minute flow rates as an environmentally correct alternative for the cutting fluid used in plunge cylindrical grinding. The small amount of lubricant is pulverized in a compressed air stream, reducing the undesirable effects by supplying lubricant and cooling. The evaluation of the technical performance of MQL in the grinding process consisted of experimentally analyzing the behavior of the tangential cutting force, $\mathrm{G}$ ratio, roughness and residual stress.

\section{Minimum Quantity Lubricant - MQL}

In line with growing environmental concerns involved in the use of cutting fluids in machining processes, as reported by several researchers and manufacturers of machine tools, strong emphasis is being placed on the development of environmentally friendly technology, i.e., on environmental preservation and the search for conformity with the ISO 14000 standard. On the other hand, despite persistent attempts to completely eliminate cutting fluids, in many cases cooling is still essential to the economically feasible service life of tools and the required surface qualities. This is particularly true when tight tolerances and high dimensional and shape exactness are required, or when the machining of critical, difficult to cut materials is involved. This makes the minimum quantity of lubrication an interesting alternative, because it combines the functionality of cooling with an extremely low consumption of fluids (usually $<80 \mathrm{ml} / \mathrm{h}$ ). These minimal quantities of oil suffice, in many cases, to reduce the tool's friction and to prevent the adherence of materials. The minimization of cutting fluids has gained increasing relevance in the past decade (Klocke et al, 1998; Simon, 1999 e Dörr \& Sahm, 2000).

The limitations of dry operations can be overcome, in many cases, through the introduction of minimum quantity lubrication systems (Near-Dry machining - MQL) that act based on the principle of total use, without residues, applying lubricant flows from 10 up to a maximum of $100 \mathrm{ml} / \mathrm{h}$ at a pressure from 4.0 to 6.5 $\mathrm{Kgf} / \mathrm{cm}^{2}$. What matters is that, even so, the chips are released in a practically dry condition, thus avoiding cutting fluid recycling costs. In this technology, the lubricating function is ensured by the oil and the cooling function is provided mainly by the compressed air. This small amount of fluid suffices to reduce friction in cutting, diminishing the tendency of adhesion in materials with such characteristics. A comparison with conventional cooling revealed numerous advantages (Klocke \& Eisenblätter, 1997; Young et al, 1997; Heisel et al, 1998; Schulz, 1999; Dörr, 1999 and Diniz, 1999).

However, compared with the conventional technique, MQL involves additional costs to pressurize the air and technological supports needed in the process in order to overcome the technological restrictions of the MQL technique. For instance, special techniques for transporting chips may be necessary, and productivity may decrease due to the thermal impact on the machined components. Oil vapor, mist and smoke generated during the use of MQL in machining can be considered undesirable byproducts, since they contribute to increase the index of airborne pollutants. This has become a factor for concern, requiring a adequate exhaustion system in the machine tool. A compressed air line that works intermittently during the process is used for atomization. These compressed air lines generate noise levels that usually exceed the legally established limits (Machado \& Diniz, 2000). Based on the known costs of wet machining and MQL machining, a comparison was made of the costs of investments and annual fixed and proportional costs at the BMW company. The comparison of the total investment costs in the transfer line, including chip cleaning equipment, confirmed the $22 \%$ financial advantages of machining with MQL technology (Dörr \& Sahm, 2000).

This technique has long been employed successfully in various metal cutting, sawing and shaping processes. The advantages it offers suggest that its range of applications will expand; however, the variables of influence to be considered and their effects on the results of the process still merit further in-depth studies. Minimum quantity lubrication systems employ mainly cutting fluids that are nonsoluble in water, especially mineral oils. Due to the very small amounts of cutting fluids used, one must consider that the costs should not prevent the use of high technology compositions in the field of basic and additive oils. Vegetal-based materials are being increasingly used. These oils, inhaled in the form of aerosol, reduce the health hazard factor (Heisel et al, 1998 and Novaski \& Dörr, 1999).

Hafenbraedl \& Malkin (2001) found that the MQL technique provides efficient lubrication, reducing the grinding power and the specific energy to a level of performance comparable or superior to that obtained from conventional soluble oil (at a $5 \%$ concentration and $5.3 \mathrm{l} / \mathrm{min}$ flow), while at the same time it significantly reduces grinding wheel wear. However, MQL presented slightly lower superficial roughness values $\left(R_{a}\right)$. The grinding performance was also evaluated in the dry condition. The results with MQL were obtained in the plunge cylindrical grinding process using quenched and tempered AISI 52100 steel with an average hardness of $60 \mathrm{HRc}$, using an aluminum oxide grinding wheel. It was expected that applying MQL to internal cylinder grinding would pose a challenge owing to the continuous nature of the process, the limited access space to lubricate and cool the grinding zone and the difficulties involved in removing the metal particles generated in the operation. To use the MQL technique, a precision doser was coupled to the grinding system, supplying ester oil at a specified flow rate (12 $\mathrm{ml} / \mathrm{h}$ ). A nozzle mixes the ester oil with compressed air at a pressure of $69 \mathrm{kPa}$ to produce a fine mist. Applying the ester oil was a difficult task because of the limited access for the nozzle, so its design was optimized to allow it to reach as close as possible to the grinding zone entrance. A cold air pistol was also used in an attempt to cool the part. The cold air $\left(-2^{\circ} \mathrm{C}\right)$ exited the nozzle at a flow rate of $3 \mathrm{l} / \mathrm{s}$ and a pressure of 7.6 bar. It was later estimated that the total quantity of available cold air would not suffice to supply significant cooling. However, the main disadvantage of MQL revealed in this test was the poor cooling it provided, which resulted in high mass temperatures and thermal expansion of the workpiece.

\section{Experimental Procedure}

The material used in these tests was annealed ABNT 4340 steel with approximately $54 \mathrm{HRc}$ hardness. Classified as tempering steel, it is employed in the manufacture of components that require a good combination of mechanical strength and toughness.

The tests were carried out with aluminum oxide $\left(\mathrm{Al}_{2} \mathrm{O}_{3}\right)$ grinding wheels having the following characteristics: (355.6 x 25.4 $\mathrm{x} 127 \mathrm{~mm}$ - FE 38A60KV) produced by the company NORTON, and with superabrasive CBN (cubic boron nitride) grinding wheels manufactured with a vitrified binder and a $25 \%$ vol. concentration of $\mathrm{CBN}$, with dimensions similar to the conventional grinding wheel (350 x 20 x 5 x 127mm - B252P240V3). The dressing operation was kept constant in all the tests, using a multigranular fliese-type dresser which did not influence the process's output variables.

A series of preliminary tests was carried out to determine the best lubricant and compressed air flow, as well as the best choice of the various types of lubricants using the MQL technology. Seven types of lubricants were subjected to preliminary testing. The LB 1000 lubricant supplied by the MQL equipment manufacturer 
displayed the best performance; therefore, all the results reported here refer to this type of lubricant.

The equipment utilized to control the minimum quantity of lubricant (MQL) was the Accu-lube supplied by ITW Chemical Products Ltd., which uses the oil supply pulse system and allows the air and lubricant flows to be adjusted separately. The creation of the nozzle allowed a compressed air flow close to that of the grinding wheel's peripheral velocity $(30 \mathrm{~m} / \mathrm{s})$. This velocity is required to enable the mixture (lubricant plus compressed air) to penetrate in the region of contact between the tool and the part, favoring their lubrication and cooling. To take precision measurements of the compressed air flow at speeds of 30 and $40 \mathrm{~m} / \mathrm{s}$, a flow meter and a pressure regulator equipped with a filter were purchased. Figure 1 shows the nozzle developed and utilized in the testing of the MQL technique in the grinding process. The nozzle was placed at a distance of about $35 \mathrm{~mm}$ from the grinding wheel-piece interface.

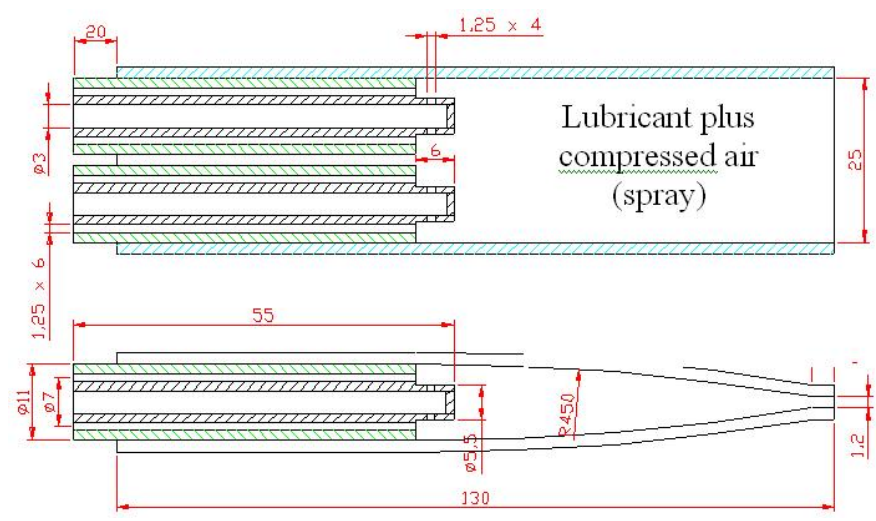

Figure 1. Design of the nozzle used in the MQL tests.

The input parameters [grinding wheel cutting speed $\left(\mathrm{V}_{\mathrm{s}}\right)$, plunge speed $\left(V_{f}\right)$, peripheral workpiece speed $\left(V_{w}\right)$, grinding depth (a) and spark out time $\left(t_{s}\right)$ ] were selected based on recommendations given in the technical literature and on preliminary testing. The cutting conditions selected after testing preliminary to the definitive tests were: $\mathrm{V}_{\mathrm{s}}=30 \mathrm{~m} / \mathrm{s} ; \mathrm{V}_{\mathrm{f}}=1 \mathrm{~mm} / \mathrm{min} ; \mathrm{V}_{\mathrm{w}}=20 \mathrm{~m} / \mathrm{min}$ (average speed); $\mathrm{a}=0.1 \mathrm{~mm}$ and $\mathrm{t}_{\mathrm{s}}=10 \mathrm{~s}$. These parameters were kept constant throughout the tests.

A synthetic emulsion in a $5 \%$ concentration was used in the conventional cooling condition. The maximum flow supplied by the pump and by the machine's original nozzle was $8.4 \mathrm{l} / \mathrm{min}$.

The workpiece roughness was measured by adjusting the rugosimeter to a cut-off length of $0.8 \mathrm{~mm}$. At the end of each test, the arithmetic mean roughness values, $R_{a}$, were measured at three different points approximately $120^{\circ}$ equidistant from each other.

The tangential cutting force was measured based on the rotation (n) of the grinding wheel and the electric power $\left(\mathrm{P}_{\mathrm{c}}\right)$ consumed by the wheel's motor during the cutting operation. To this end, a signal conditioning circuit was used, which allows the motor's electric current, voltage and rotation to be recorded and transformed into compatible electric voltage signals to be sent to an A/D data acquisition board. The data originating from the process were then converted from analogical to digital mode, using a 12-bit data conversion board manufactured by National Instruments, specification PCI-6111E, which was installed in a Pentium III, 700 $\mathrm{MHz}$ PC microcomputer. The interface software between the board and the computer was LabView 6. It should be noted that the effective tangential cutting force was calculated by subtracting the empty tangential force after the machine reached the stable mode.

The grinding wheel's performance was evaluated based on the diametral wear of the grinding wheel. The tests were conducted using $15 \mathrm{~mm}$ of the grinding wheel's width $(25 \mathrm{~mm})$, the portion unused in the test serving as a reference to measure the diametral loss of the grinding wheel by the wear profile impression method. Upon concluding of each test, the grinding wheel's geometric profile was marked on a test specimen, built out of low carbon steel (ABNT 1020), specifically for that purpose was used for subsequent measurement of the grinding wheel's wear.

The nominal values of residual stress was determined based on the method of multiple exposition $\left(\operatorname{sen}^{2} \Psi\right)$, following the SAE J784a code. In this procedure, the normal residual stress and the residual shear stress are evaluated by adjusting (d) versus $\left(\operatorname{sen}^{2} \Psi\right)$ curves for an elliptically shaped curve, where (d) is the interplanar distance of the analyzed crystallographic plane and $(\Psi)$ is the angle of the sample's slope. For experimental reasons, our choice fell on the analysis of the (211) plane of the ferrite and martensite using the values of modulus of elasticity and Poisson's coefficient. Cobalt radiation was employed to determine the residual stress, with a scanning angle (20) varying from 47 to 63 degrees, in 0.1 degree steps and an exposure time of 2 seconds. The sample's slope angles varied from -60 to 60 degrees, with measurements taken at 10 degree intervals.

\section{Results and Discussion}

The results below refer to the best cutting, lubrication and cooling conditions found in the plunge cylindrical grinding of quenched and tempered ABNT 4340 steel for the parameters evaluated here.

\section{Measurement of the Tangential Cutting Force}

Figures 2 to 5 compare the tangential cutting force values obtained from the aluminum oxide $\left(\mathrm{Al}_{2} \mathrm{O}_{3}\right)$ grinding wheel using conventional cooling $(8.4 \mathrm{l} / \mathrm{min})$ and the MQL technique. The values were obtained after 3 stages and 30 cycles, each cycle of $100 \mu \mathrm{m}$. It is worth noting that each point on the graphs corresponds to an arithmetical average of the maximum points obtained in the three repetitions of the test.

In general, the results produced by the MQL technique showed lower tangential cutting force values than those obtained with the conventional system. This behavior allows to state that the MQL system was able to more efficiently penetrate into the region of contact between the grinding wheel and the piece.

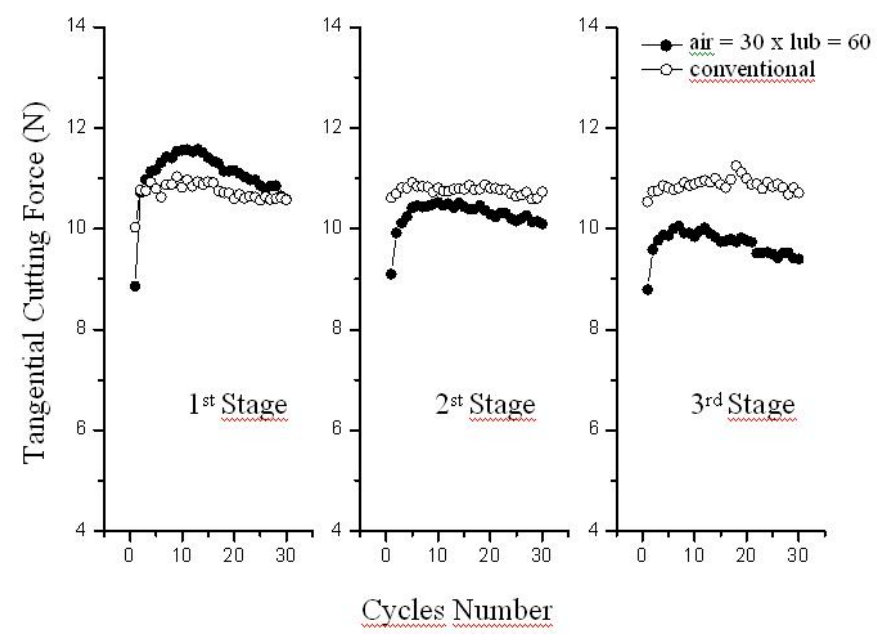

Figure 2. Tangential cutting force during 90 cycles with $\mathrm{Al}_{2} \mathrm{O}_{3}$ wheel $\left(V_{s}=30 \mathrm{~m} / \mathrm{s} ; V_{f}=1 \mathrm{~mm} / \mathrm{min} ; \mathrm{a}=100 \mu \mathrm{m} ; V_{\text {air }}=30 \mathrm{~m} / \mathrm{s}\right.$ and $\left.V_{\text {lubri. }}=60 \mathrm{ml} / \mathrm{h}\right)$. 


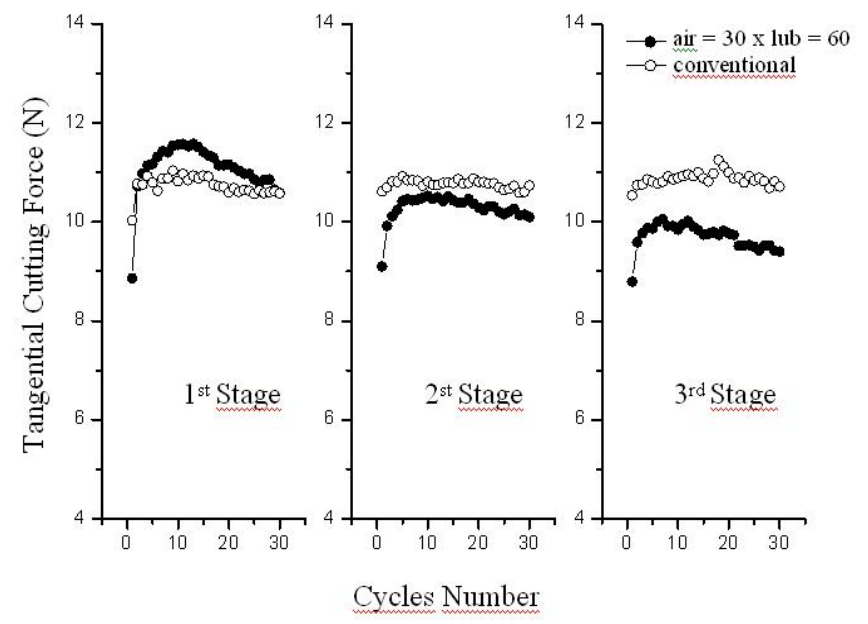

Figure 3. Tangential cutting force during 90 cycles with $\mathrm{Al}_{2} \mathrm{O}_{3}$ wheel $\left(V_{s}=30 \mathrm{~m} / \mathrm{s} ; V_{f}=1 \mathrm{~mm} / \mathrm{min} ; \mathrm{a}=100 \mu \mathrm{m} ; V_{\text {air }}=40 \mathrm{~m} / \mathrm{s}\right.$ and $\left.V_{\text {lubri. }}=60 \mathrm{ml} / \mathrm{h}\right)$.

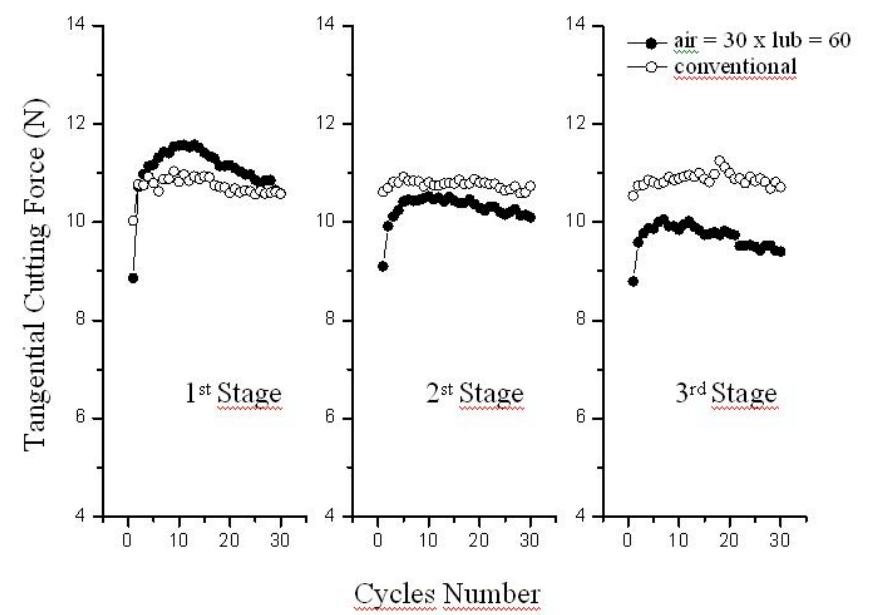

Figure 4. Tangential cutting force during 90 cycles with $\mathrm{Al}_{2} \mathrm{O}_{3}$ wheel $\left(V_{s}=30 \mathrm{~m} / \mathrm{s} ; V_{f}=1 \mathrm{~mm} / \mathrm{min} ; \mathrm{a}=100 \mu \mathrm{m} ; V_{\text {air }}=30 \mathrm{~m} / \mathrm{s}\right.$ and $\left.V_{\text {lubri. }}=40 \mathrm{ml} / \mathrm{h}\right)$.

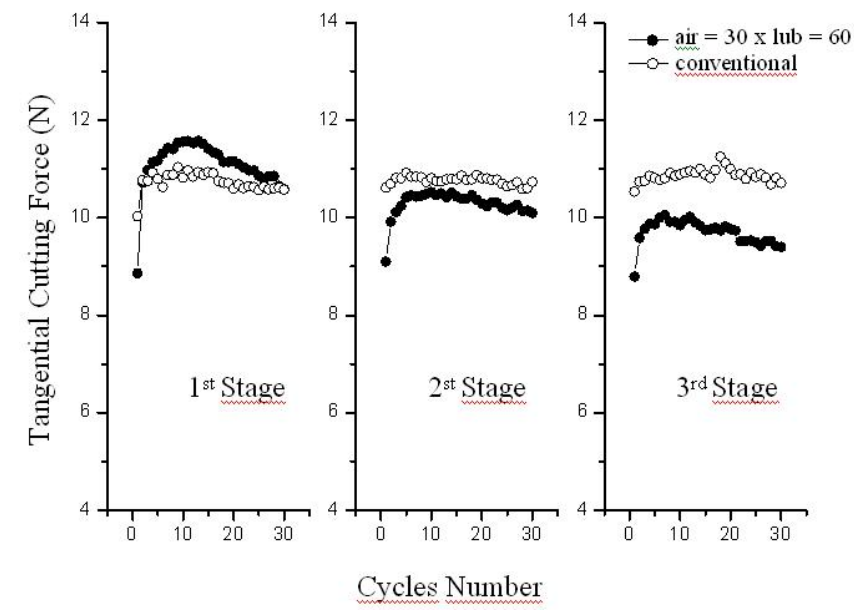

Figure 5. Tangential cutting force during 90 cycles with $\mathrm{Al}_{2} \mathrm{O}_{3}$ wheel. $\left(V_{s}=30 \mathrm{~m} / \mathrm{s} ; V_{f}=1 \mathrm{~mm} / \mathrm{min} ; a=100 \mu \mathrm{m} ; V_{\text {air }}=40 \mathrm{~m} / \mathrm{s}\right.$ and $\left.V_{\text {lubri. }}=40 \mathrm{ml} / \mathrm{h}\right)$.

Because of its excellent lubricating property, the lubricant utilized with the MQL technique allowed the angle cutting capacity of the aluminum oxide grinding wheel to remain sharp for a longer working period.
Attention should be drawn to the fact that, due to the small area of action of the air/lubricant flow in the MQL system, the precise positioning of the spray nozzle can significantly affect the lubricating and cooling capacity and, hence, the tangential cutting force values. The introduction of an effective lubricant into the cutting region reduces the amount of heat generated by friction by reducing the grinding wheel/piece contact, eliminating the need for large amounts of fluid. Moreover, with efficient lubrication, the chips slide more efficiently over the face of the tool, reducing the consumption of energy.

The speed at which the fluid penetrates the cutting region is crucial. When the fluid's speed is equal to or higher than the peripheral velocity of the grinding wheel, the fluid tends to penetrate the cutting region at the same velocity as the abrasive grains, so that these grains do not exert any significant interference during the removal of material.

When using the MQL technique, the tangential cutting force values decreased as the test progressed, probably due to the presence of lubricant in the periphery of the grinding wheel, improving the slipping of the grains between the tool and the piece. On the other hand, the peripheral velocity of the piece was reduced, since its rotation was kept constant, providing a lower tangential cutting force. The test conducted with conventional cooling showed a certain stabilization of the tangential cutting force, possibly through the loss of the material removal capacity.

The tool's loss of sharpness generated by the macroeffect during dressing probably did not affect the behavior of the tangential cutting force, since the tool's abrasive wear was minimal, as shown later.

Figures 6 and 7 compare the tangential cutting force values obtained with the CBN grinding wheel under the same lubrication and cooling conditions as those applied for the $\mathrm{Al}_{2} \mathrm{O}_{3}$ grinding wheel.

Because of the unsatisfactory surface roughness and diametral wear results obtained with the CBN grinding wheel and the high cost of the abrasive tool with vitrified binder (approximately 120fold higher than the aluminum oxide grinding wheel), it was decided not to test it under all the lubrication and cooling conditions. On the other hand, the CBN grinding wheel presented an extremely high hardness. Due to poor lubrication and cooling when the MQL technique is used, the use of a grinding wheel of medium to soft hardness is feasible. It is important to point out that the use of superabrasive grinding wheels is recommended for very high peripheral velocities (over $80 \mathrm{~m} / \mathrm{s}$ ) in machines for high removal rates and high rigidity, which was not possible with the machine utilized here and which led to unsatisfactory results.

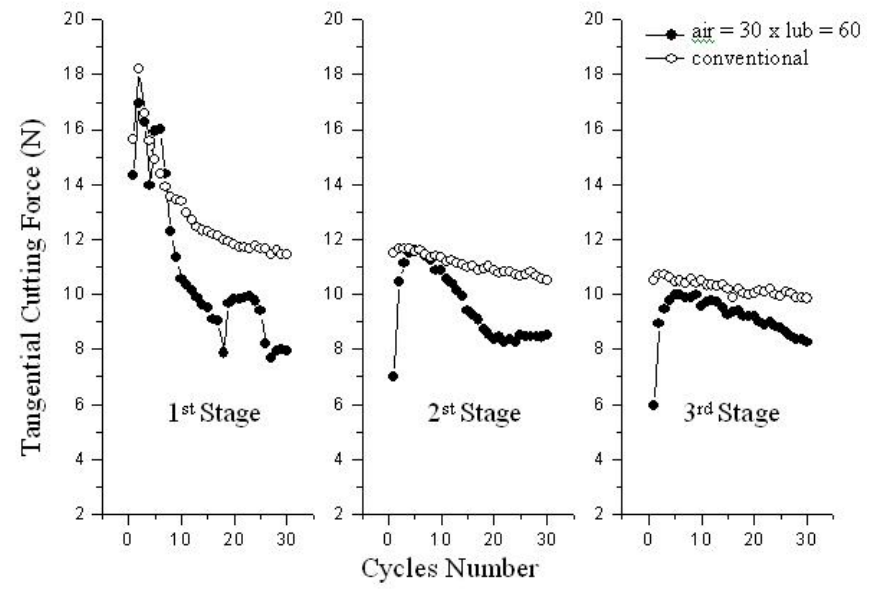

Figure 6. Tangential cutting force during 90 cycles with $\mathrm{CBN}$ wheel $\left(V_{s}=30 \mathrm{~m} / \mathrm{s} ; V_{f}=1 \mathrm{~mm} / \mathrm{min} ; \mathrm{a}=100 \mu \mathrm{m} ; V_{\text {air }}=30 \mathrm{~m} / \mathrm{s}\right.$ and $\left.V_{\text {lubri. }}=60 \mathrm{ml} / \mathrm{h}\right)$. 


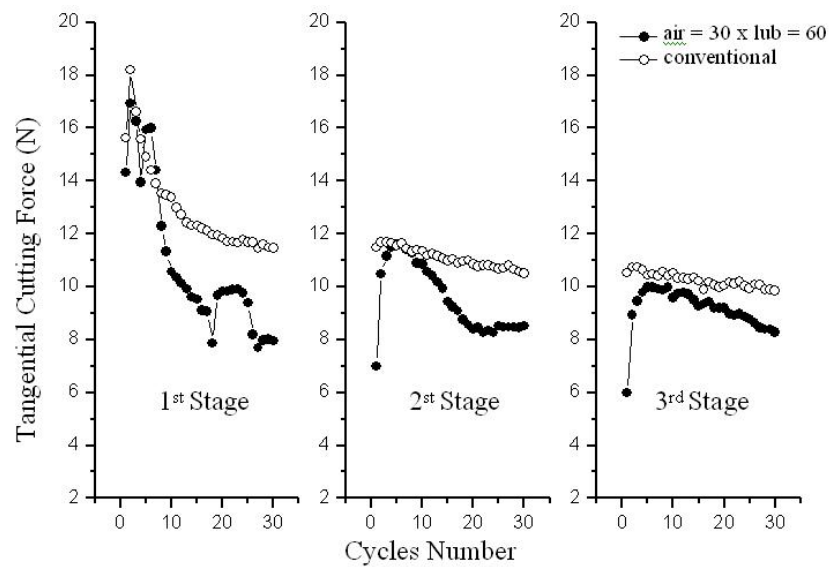

Figure 7. Tangential cutting force during 90 cycles with CBN wheel $\left(V_{s}=30 \mathrm{~m} / \mathrm{s} ; V_{f}=1 \mathrm{~mm} / \mathrm{min} ; \mathrm{a}=100 \mu \mathrm{m} ; V_{\text {air }}=30 \mathrm{~m} / \mathrm{s}\right.$ and $\left.V_{\text {lubri. }}=40 \mathrm{ml} / \mathrm{h}\right)$.

Comparing figures 6 and 7 showing the performance of aluminum oxide and CBN grinding wheels reveals that the lowest tangential forces were obtained with the CNB grinding wheel, especially in the third stage. This was due to the lower energy consumed in grinding with this wheel, which possesses higher hardness of their grains (the Knoop hardness of the CBN grain is 4,500 while that of the $\mathrm{Al}_{2} \mathrm{O}_{3}$ grain is $2,500 \mathrm{~kg} / \mathrm{mm}^{2}$ ), (Felipe Jr., 1992).

The excellent maintenance of sharpness provided by the superabrasive CBN grinding wheel combined with the exceptional lubricating power of the fluid utilized when applying the MQL technique led to a significant reduction of the tangential force as the tests progressed when compared with the cooled condition. Again, it should be noted that, owing to the small area of action of the air/lubricant flow in the MQL system, the lack of precise positioning of the spray nozzle may significantly affect the lubricating and cooling capacity and, thus, the tangential cutting force values.

A comparison of the two cutting fluid application systems revealed that the CBN grinding wheel and the aluminum oxide grinding wheel produced similar tangential cutting force values. However, in the initial cycles, the CBN wheel presented higher tangential cutting force values under all lubrication and cooling conditions tested here. With the use of MQL, the microeffect caused the cutting edges of the CBN grinding wheel to be renewed continually along the process, thus maintaining the grinding wheel's self-sharpening capacity and leading to a gradual decrease in the tangential cutting force values during the tests. Nevertheless, this condition led to substantial wear. An analysis of figure 8 illustrating the CBN grinding wheel wear reveals this behavior.

\section{Measurement of the Grinding Wheel's Diametral Wear}

The tests were carried out using $15 \mathrm{~mm}$ of the total width of the grinding wheel. Thus, the portion not used in the test served as a reference to measure the grinding's wheel's diametral wear. Figure 8 compares the diametral wear values using $\mathrm{Al}_{2} \mathrm{O}_{3}$ and $\mathrm{CBN}$ grinding wheels with conventional cooling $(8.4 \mathrm{l} / \mathrm{min})$, dry cooling, and the MQL technique under various lubrication and cooling conditions. The values obtained after 3 stages and 30 cycles, each cycle of $100 \mu \mathrm{m}$, added up to a total removal of $9 \mathrm{~mm}$ from the part's diameter. Again, one can see that the application of MQL produced a superior result when compared with the use of conventional cutting fluid, possibly due to the excellent lubricating capacity in the region of contact between the grinding wheel and the work piece.

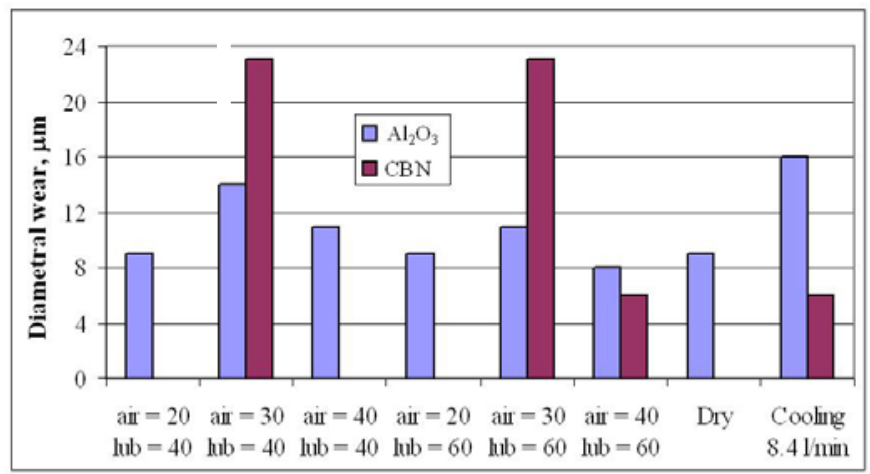

Figure 8. Diametral wear after 90 cycles using $\mathrm{Al}_{2} \mathrm{O}_{3}$ and $\mathrm{CBN}$ grinding wheels $\left(V_{\text {air }}=\mathrm{m} / \mathrm{s} ; V_{\text {lubri. }}=\mathrm{ml} / \mathrm{h} ; \mathrm{V}_{\mathrm{s}}=30 \mathrm{~m} / \mathrm{s} ; \mathrm{V}_{\mathrm{f}}=1 \mathrm{~mm} / \mathrm{min} ; \mathrm{a}=100 \mu \mathrm{m}\right.$ and $\left.t_{s}=10 s\right)$.

The grinding wheel's diametral wear originates from several phenomena resulting from the friction between the abrasive grains and the part. The different lubrication and cooling conditions led to different grinding wheel diametral wear results. Higher fluid lubricating power reduces the wear on the grinding wheel by decreasing grain-part friction and chip-binder friction, allowing the abrasive grains to remain bound to the binder for longer periods and leading to lower wear of the tool. Greater diametral wear of the aluminum oxide grinding wheel was observed with conventional cooling, possibly due to the lower lubricating capacity of the cutting fluid employed. It was found that the use of MQL under all the lubrication and cooling conditions led to a superior performance than conventional cooling. However, this behavior was not repeated with the CBN grinding wheel, probably because of the high hardness of the CBN tool used here, which resulted in macro-wear caused by the intense friction between chips and binder.

It was found that a superior performance could be achieved using the conventional cutting fluid and the machine's original nozzle with the CBN grinding wheel than with the aluminum oxide grinding wheel. This finding confirmed the considerable difference in the wear phenomenology of the superabrasive grinding wheel.

The application of cutting fluid with MQL allowed the aluminum oxide grinding wheel's cutting edges to remain sharp for longer periods before they were renewed. A marked difference was also found in the wear of the aluminum oxide and the CBN grinding wheels. The aluminum oxide grinding wheel displayed an excellent performance with the MQL system. However, the CBN grinding wheel's diametral wear did not show a standard behavior with MQL, i.e., it showed lower and higher values in comparison with the conventional cooling condition. Again, it should be pointed out that the CBN grinding wheel used here presented an extremely high hardness in service, resulting in macro-wear during the machining operation. Because of the poor lubrication and cooling provided by the MQL technique, it is feasible to use a grinding wheel of medium to soft hardness. On the other hand, the use of superabrasive grinding wheels is recommended for very high peripheral speeds in machines supplying high rates of removal and high rigidity, which was not possible with the machine utilized here, thus producing unsatisfactory results.

The finding that grinding without cutting fluid results in less wear than with cooling does not seem logical. However, in the condition without cutting fluid, the heat generated at the grinding wheel-workpiece interface is greater, leading to lower resistance of the material and thus allowing for lower tangential cutting force and specific energy, as discussed earlier, and therefore, less grinding wheel wear. Although it was not observed, it is possible that there was a small area of adherence of the material on the grinding wheel surface. This accumulation of material may have made the decrease 
in grinding wheel diameter seem smaller, which suggest a greater diametral wear. This adherence also leads to a poorer finish, as will be discussed in the item below.

The MQL technique led to a 13 to $50 \%$ reduction in diametral wear of the aluminum oxide grinding wheel in comparison with the conventional cooling system. However, the use of the CBN grinding wheel failed to produce a standard behavior.

\section{Roughness of the Ground Part}

It is well known that the surface finish can significantly affect the mechanical strength of components when the latter are subjected to fatigue cycles. Figure 9 compares the mean values of the $\mathrm{R}_{\mathrm{a}}$ parameter with the $\mathrm{Al}_{2} \mathrm{O}_{3}$ grinding wheel using the conventional (flooding) condition against those obtained with the MQL technique. The values were obtained after 3 stages and 30 cycles, each cycle of $100 \mu \mathrm{m}$. Six measurements were taken of the $R_{a}$ variation in three different positions equidistant from each other by about $120^{\circ}$. The results are shown in Fig. 9.

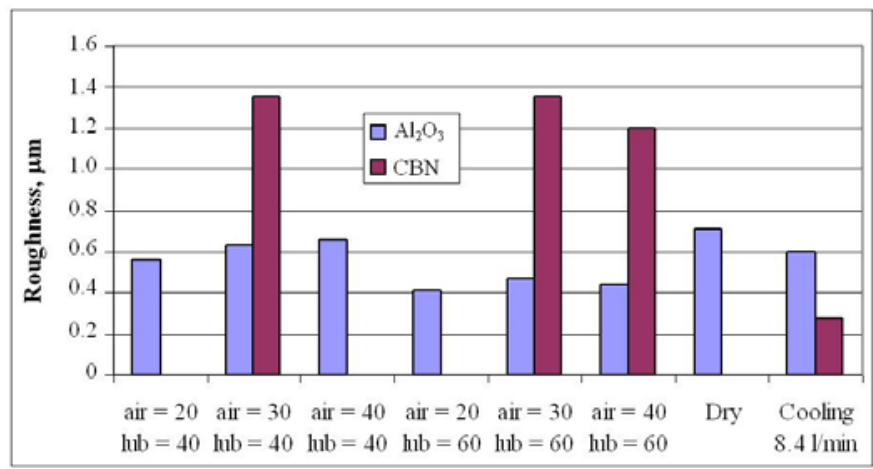

Figure 9. Roughness $\left(R_{a}\right)$ after 90 cycles using $\mathrm{Al}_{2} \mathrm{O}_{3}$ and $\mathrm{CBN}$ grinding wheels $\left(V_{\text {air }}=\mathrm{m} / \mathrm{s} ; V_{\text {lubri. }}=\mathrm{ml} / \mathrm{h} ; \mathrm{V}_{\mathrm{s}}=30 \mathrm{~m} / \mathrm{s} ; \mathrm{V}_{\mathrm{f}}=1 \mathrm{~mm} / \mathrm{min}\right.$ and $\left.\mathrm{a}=100 \mu \mathrm{m}\right)$.

The surface roughness of a machined part is mainly affected by the size of the abrasive grain, dressing conditions, material removal rate, spark-out time and lubrication and cooling conditions. Generally speaking, the basic characteristic of emulsion is its effective removal of heat from the work piece, albeit low lubrication of the system affects the surface roughness value. On the other hand, the MQL technique provides efficient lubrication, reducing the grinding power and the specific energy while simultaneously improving the surface quality, despite its low cooling capacity. The type of grinding wheel (CBN or aluminum oxide) also influences the surface roughness values, since $\mathrm{CBN}$ grinding wheels have a greater cutting capacity throughout the process, being more resistant to abrasive wear than the conventional grinding wheel.

An analysis of the results of applying conventional cutting fluid and the MQL technique indicated that, in general, the application of cutting fluid with $\mathrm{MQL}$ to the $\mathrm{Al}_{2} \mathrm{O}_{3}$ wheel resulted in a performance superior to that of the conventional method, possibly by providing greater fluid penetration efficiency into the cutting region. However, it was found that, for the lubrication and cooling conditions $\left(\mathrm{V}_{\text {lubri. }}=60 \mathrm{ml} / \mathrm{h}\right)$, the surface finish improved significantly with the use of the MQL technique. It is worth pointing out that no significant thermal dilation was found at the end of the cycle when using MQL, indicating that the use of this fluid combined with compressed air provided adequate cooling.

Due to the unsatisfactory results obtained with the CBN grinding wheel using MQL and the high cost of the abrasive tool, it was decided not to test it under all the lubrication and cooling conditions to which the aluminum oxide grinding wheel was subjected. It should be noted that the poorer performance of the
CBN grinding wheel with MQL was probably due to the tool's extremely high hardness in service, causing it to show macro-wear and leading to greater surface roughness. On the other hand, the quality of the CBN grinding proved unreliable, and its cost was approximately $50 \%$ higher than the prices of grinding wheels manufactured by well known manufacturers.

In general, the MQL technique produced lower surface roughness under most lubrication and cooling conditions using the $\mathrm{Al}_{2} \mathrm{O}_{3}$ grinding wheel, probably because of the effective lubrication of the tool's abrasive grains in the cutting region. With efficient lubrication, the chip slips across the tool's surface more easily, thus allowing for a better surface finish. With MQL, the lowest superficial roughness $\left(\mathrm{R}_{\mathrm{a}}\right)$ found was $0.41 \mu \mathrm{m}$, using the $\mathrm{Al}_{2} \mathrm{O}_{3}$ grinding wheel, compared with $0.60 \mu \mathrm{m}$ in the cooled condition. Using conventional cooling with the CBN grinding wheel led to a better finish than with MQL.

Again, the finding that grinding without cutting fluid resulted in a surface finish comparable to that resulting from the various lubricating and cooling conditions seems questionable, for it was expected that the pores of the grinding wheel would become clogged and that material would adhere to the grinding wheel surface, resulting in a poorer finish. It is important to emphasize that the dry condition caused the work piece to become very hot, making it impossible to remove it from the machine without protective gloves. Very high temperatures cause thermal dilation of the part, which may lead to imprecision in its diameter, impairing one of the main functions of the grinding process since the purpose of grinding is normally to confer tight dimensional tolerances on a piece.

As discussed previously, a superior performance can be achieved using the conventional cutting fluid and the machine's original nozzle with the $\mathrm{CBN}$ grinding wheel than with the aluminum oxide grinding wheel. The CBN grinding wheel produced an $R_{a}$ of $0.28 \mu \mathrm{m}$ while the oxide aluminum $0.60 \mu \mathrm{m}$.

Satisfactory results in terms of surface quality have also been achieved with the MQL technique in various machining processes with defined geometries using a variety of materials, as reported by Wakabayashi (1998), Dörr \& Sahm (2000) and Silva (2002).

\section{Measurement of Residual Stress}

The grinding process inevitably leads to residual stresses in the area surrounding the finished surface, which may affect the material's mechanical behavior.

Due to the high cost of inspections, the residual stress of only 10 samples was analyzed without replicates. However, based on a preanalysis of the dry condition during the tests, it was decided to measure the residual stresses under the dry condition in order to compare the behavior of the residual stresses under the 3 conditions (conventional, MQL and dry cooling). This parameter was analyzed after 3 stages and 30 cycles, each cycle being $100 \mu \mathrm{m}$, with a total removal of $9 \mathrm{~mm}$ of the diameter of the test specimen.

Figure 10 shows the values of residual stress displayed by the samples using the aluminum oxide and CBN grinding wheels with conventional cooling $(8.4 \mathrm{l} / \mathrm{min})$, dry cooling and MQL under various lubrication and cooling conditions. To identify the effect of the grinding process on the residual stresses, it was decided to measure the residual stress after turning followed by heat treatment.

As indicated in the literature review, grinding can lead to microstructural transformations due to high temperatures and displacement of the austenite in relation to the carbon, which helps diffusion. This may cause tensile or compressive stresses, depending on the material that is being ground and on the machining conditions. The superior behavior of the MQL technology was also confirmed by the residual stress results. 


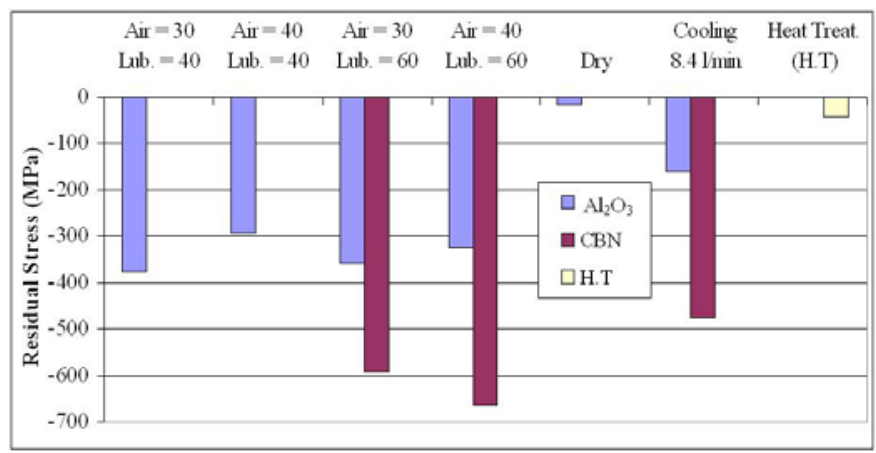

Figure 10. Comparative results of residual stress at a depth of approximately $10 \mu \mathrm{m}$ below the surface after 90 cycles using $\mathrm{Al}_{2} \mathrm{O}_{3}$ and CBN grinding wheels $\left(V_{\text {air }}=\mathrm{m} / \mathrm{s} ; V_{\text {lubri. }}=\mathrm{ml} / \mathrm{h} ; V_{\mathrm{s}}=30 \mathrm{~m} / \mathrm{s} ; \mathrm{V}_{\mathrm{f}}=1 \mathrm{~mm} / \mathrm{min}\right.$; $a=100 \mu \mathrm{m}$ and $\left.t_{s}=10 \mathrm{~s}\right)$.

Residual stresses are induced by nonuniform plastic deformations in the proximities of the surface of the work piece. According to Malkin (1989) and Weingaertner et al. (2001), residual stresses may be caused by three factors: influence of thermal expansion, influence of microstructural transformations in the part, and mechanical influence. Thermal expansion in grinding is proportional to the temperatures generated in the process. The temperature in external layers is high, gradually decreasing in the internal layers in the direction of the core. In grinding, when the source of heat is active, the external layers expand more than the internal ones, leading to residual compressive stress on the surface. When the heat source is no longer active (cooling), the external layer should contract more, which is not permitted by the lower layers. The mechanical influence derives from the penetration of the abrasive grain into the piece. The causes for this phenomenon can be compared with shot peening. In this analogy, the abrasive grain can be compared with a hardened steel ball.

A comparative analysis of the residual stress values shows that these were present with the two abrasive tools and lubrication/cooling conditions, varying only in intensity. Residual compressive stresses are considered beneficial for the mechanical properties of materials, increasing their resistance to fatigue and exerting a strong impact on the service life of components, while tensile stresses compromise the mechanical strength, corrosion and wear resistance. These properties are important for the load/force mechanisms when using tempered ABNT 4340 steel.

The use of the MQL technique was found to give rise to higher residual compressive stresses under all the lubrication/cooling conditions than did the conventional cooling system with both types of abrasive tools, which is a positive aspect. The highest residual compressive stress obtained with the aluminum oxide grinding wheel using MQL under the condition of $\left(\mathrm{V}_{\text {air }}=30 \mathrm{~m} / \mathrm{s}\right.$ and $\mathrm{V}_{\text {lubri. }}=$ $40 \mathrm{ml} / \mathrm{h}$ ) was $-376 \mathrm{MPa}$ against $-160 \mathrm{MPa}$ provided by the cooled condition, representing a $135 \%$ increase in residual compressive stress. The lowest value found for the $\mathrm{Al}_{2} \mathrm{O}_{3}$ grinding wheel was 293MPa under the condition of $\left(\mathrm{V}_{\text {air }}=40 \mathrm{~m} / \mathrm{s}\right.$ and $\left.\mathrm{V}_{\text {lubri. }}=40 \mathrm{ml} / \mathrm{h}\right)$, which was also higher than that found with the conventionally cooled condition.

An analysis of the two abrasives indicated that the CBN grinding wheel produced higher residual compressive stress under all the lubrication and cooling conditions tested. Using the CBN tool with the MQL technique also produced higher residual compressive stresses than with conventional cooling. The highest residual compressive stress produced by the CBN grinding wheel was 664MPa compared with $-476 \mathrm{MPa}$ using conventional cooling. The superior performance of the CBN grinding wheel was already expected, since the conditions of temperature and deformation are favorable with this tool, mainly due to the high thermal conductivity of the CBN grains.

In comparison to machining without cooling, a significant increase was found in the residual compressive stresses under all the lubrication/cooling conditions tested with the $\mathrm{Al}_{2} \mathrm{O}_{3}$ grinding wheel. As discussed previously, this residual stress behavior was expected, since the dry condition provides higher temperature in the cutting region, most of this heat going to the part, followed by slow cooling, probably modifying the microstructure near the surface of the part.

According to Minke (1999), lubrication during the grinding process acts decisively on the part's surface integrity. The high level of friction during grinding is an extremely important factor contributing to the final condition of the machined piece. Nevertheless, the superior performance achieved through the application of MQL derived mainly from the high lubricity of the fluid employed, resulting in the reduction of the part wheel friction coefficient and preserving the grinding wheel's sharpness.

Analyzing the condition of residual stress after heat treatment, it was found that the grinding conditions defined during the tests led to a significant increase in the residual compressive stress values, conferring beneficial characteristics on the mechanical properties of the tested piece and resulting in improved surface integrity.

Malkin (1989) stated that the introduction of CBN grinding wheels to replace aluminum oxide grinding wheels has allowed residual compressive stresses to be attained. The behavior of the residual stress using the CBN grinding wheel displayed a better performance under all the lubrication/cooling conditions when compared with the aluminum oxide grinding wheel. The CBN grinding wheel provided higher residual compressive stresses, which is beneficial to the mechanical properties of materials, increasing their fatigue strength and, hence, the service life of components. This behavior was expected and was due to the reduction of the temperatures generated during grinding with CBN grinding wheel, mainly due to the high thermal conductivity of its grains, which allows a greater portion of the generated heat to flow through the grinding wheel, reducing the partition of energy introduced into the piece.

\section{Conclusions}

An analysis of the experimental data of this study led us to reach the following conclusions regarding the plunge cylindrical grinding of tempered ABNT 4340 steel:

The analyses of the various results indicated that the MQL technique can be applied efficiently in the grinding process, providing environmentally friendly and technologically relevant gains.

The $R_{a}$ and diametral wear values were substantially reduced with the use of the MQL technique, displaying excellent properties of lubricity.

The aluminum oxide grinding wheel provided a better surface finish than the CBN grinding wheel when using the MQL technique. However, the CBN grinding wheel presented lower surface roughness $\left(R_{a} 0.28 \mu m\right)$ than the aluminum oxide grinding wheel $\left(R_{a}\right.$ $=0.60 \mu \mathrm{m}$ ) under conventional cooling.

The MQL technique reduced the tangential cutting force to a certain extent compared with the conventional cooling condition.

The tangential cutting force was decreased with MQL, possibly due to the presence of lubricant around the grinding wheel, providing better slipping of the grain at the piece-tool interface.

No significant clogging of the grinding wheel pores was found with the MQL technique.

The application of cutting fluid with MQL allowed the cutting edges of the grinding wheel to remain sharp for longer periods before they were renewed. 
The comparative analysis of the residual stress values showed that residual compressive stresses were obtained under all the lubrication/cooling conditions and types of abrasive tools employed. The highest residual compressive stress obtained with the aluminum oxide grinding wheel with MQL under the condition of $\left(\mathrm{V}_{\text {air }}=30 \mathrm{~m} / \mathrm{s}\right.$ and $\mathrm{V}_{\text {lubri. }}=40 \mathrm{ml} / \mathrm{h}$ ) was $-376 \mathrm{MPa}$ against the $-160 \mathrm{MPa}$ attained with conventional cooling, representing a $135 \%$ increase in residual compressive stress.

Comparing the two wheels indicated that the CBN wheel produced higher residual compressive stress values under all the lubrication/cooling conditions tested. An increase in residual compressive stress was also found when applying the MQL technique compared with the conventional cooling system with the CBN grinding wheel.

The flow rates selected for application with MQL did not result in dispersion of the mist, contributing toward environmentally correct manufacturing and allowing for easy viewing of the grinding operation.

The results allowed us to demonstrate that the method and quantity of lubricant and cooling are factors that influence the grinding process.

\section{Acknowledgments}

The authors are indebted to FAPESP (Brazil) for its financial support of this research, to CNPq (Brazil) for a fellowship granted through the IFM - Fábrica do Milênio project, and to Microquímica (Brazil) for its donation of the lubricant used in the preliminary tests.

\section{References}

Brockhoff, T., Walter, A., "Fluid Minimization in Cutting and Grinding”, Abrasives Magazine, Oct/Nov, 1998, p. 38-42.

Diniz, A. E., "Minimal Lubrication in the Drilling Process of Aluminum Silicon Alloy", $3^{\text {rd }}$ International Machining \& Grinding Conference, Oct., 1999, p. 683-697.

Dörr, J., "New Perspectives in Dry Machining”, Fourth International Congress of High Technology - Technological Innovations in the Manufacture, Unimep, Piracicaba, SP, Brazil, Aug., 1999.

Dörr, J., Sahm, A., "The Minimum Quantity Lubricant evaluated by the users”, Machines and metals magazine, No. 418, Brazil, Nov, 2000, p. 2039.
Dunlap, C., "Should you Try Dry?”, Cutting Tool Engineering, vol. 49, No.1, Febr., 1997, p. 22-33.

Hafenbraedl, D., Malkin, S., "Technology environmentaly correct for intern cylindrical grinding”, Machines and metals magazine, July, No.426, 2001, p. 40-55.

Heisel, U., Lutz, D., Wassmer, R., Walter, U., “The Minimum Quantity Lubricant technique and its application in the cutting process", Machines and metals magazine, Brazil, No.386, Febr., 1998, p. 22-38.

Klocke, F., Eisenblätter, G., "Dry Cutting", Annals of the CIRP, Vol. 46, No.2, 1997, p. 519-526.

Klocke, F., Schulz, A., Gerschwiler, K., Rehse, M., "Clean Manufacturing Technologies - The Competitive Edge of Tomorrow?”, The International Journal of Manufacturing Science \& Production, Vol.1, No.2, 1998, pp. 77-86.

Machado, A. R., Diniz, A. E., "Advantages and disadvantages of the use of the cutting fluids”, Machining Congress 2000, São Paulo, SP, Brazil, 2000.

Malkin, S., "Grinding mechanisms e grinding temperatures and thermal damage”, In: MALKIN, S. Grinding Technology: theory and applications of machining with abrasives, 1.ed. Chichester, Ellis Horwood Limited, 1989, p.108-171.

Minke, E., "Contribution to the role of coolants on grinding process and work results”, In: 3rd International Machining \& Grinding Conference, , Cincinnati, Ohio, October 4-7, 1999, p. 13-32.

Novaski, O., Dörr, J., “Usinagem sem refrigeração”, Máquinas e Metais, No.399, 1999, p.18-27.

Sahm, D., Schneider, T., "The production without coolant is interesting and must be more kown”, Machines and metals magazine, No. 367, Aug., Brazil, 1996, p. 38-55.

Schulz, H., "Trends in Manufacturing Technology at the Threshold of the Millennium”, Fourth International Congress of High Technology Technological Innovations in the Manufacture, Unimep, Piracicaba, SP, Brazil, Aug., 1999.

Silva, L. R., "Study of the geometry of cutting tools applied in the turning...”, Doctorate Tesis, USP/EESC/SEM, São Carlos, SP, Brazil, 2002.

Simon, T. A., "The current stage of the technology of the machinestool”, Machines and metals magazine, Brazil, Febr., 1999, p. 88-108.

Wakabayashi, T., Sato, H., Inasaki, I., "Turning using extremely small amounts of cutting fluids”, JSME International Journal, Vol.41, No.1, 1998, p.143-148.

Weingaertner, W. L., Taborga, A. R. M., Taborga, J. D. M., “Analysis of thermal damages in grinding”, In: COBEM 2001, Nov. 26-30, Uberlândia, MG, Brazil, 2001.

Young, P., Byrne, G., Cotterell, M., "Manufacturing and the Environment", The International Journal of Advanced Manufacturing Technology, Vol.13, 1997, p. 488-493. 